\title{
Potential Application of Ionic Liquids in Pharmaceutical Dosage Forms for Small Molecule Drug and Vaccine Delivery System
}

\author{
Mohammad Uddin*1, Debasish Basak ${ }^{1}$, Robert Hopefl ${ }^{1}$ and Babak Minofar ${ }^{2,3}$ \\ 1. College of Pharmacy, Larkin University, Miami, FL 33169, USA. ${ }^{2}$ Center for Nanobiology and Structural Biology, Institute \\ of Microbiology, Academy of Sciences of the Czech Republic, Zamek 136, Nové Hrady, Czech Republic. \\ 3. Faculty of Science, University of South Bohemia, Branišovská 1760, 37005 České Budějovice, Czech Republic.
}

Received, February 29, 2020; Revised, April 29, 2020; Accepted, May 5, 2020; Published, May 10, 2020.

\begin{abstract}
Ionic liquids are salts in which the ions are poorly coordinated, which causes them to exist in liquid form below $100^{\circ} \mathrm{C}$, or at room temperature. Therefore, these are also defined as room temperature ionic liquids (RTILs). In ionic liquids, at least one ion has a delocalized charge and one component is organic, which prevents the formation of a stable solid form of crystal lattice. Physical properties of ionic liquids, such as melting point, viscosity, and solubility of starting materials and other solvents, are impacted by the substituents on the organic component and by the counterions. Many ionic liquids have even been developed to address specific synthetic problems and that is the reason these are also termed as "designer solvents". Ionic liquids are considered as "green solvents" that exhibit several unique characteristics such as high ionic conductivity, high solvation power, thermal stability, low volatility, and recyclability. Although very useful with several advantages, ionic liquids have some limitations that include high cost and ease of recycling. Moreover, the toxicity and biodegradability of ionic liquids are not yet well understood. Nonetheless, ionic liquids can potentially be used in the field of pharmacy in drug design and formulation development. In drug or vaccine dosage formulation development, ionic liquids can be used as a solubility enhancer, permeability enhancer, stabilizer, targeted delivery inducer, stealth property provider or bioavailability enhancer. In this article we reviewed the physical properties of ionic liquids and potential application of ionic liquids in developing formulations for vaccines and small molecule drugs (A table has been added).
\end{abstract}

Keywords: Ionic liquid; Stabilizer; Solubility enhance; Permeability enhancer; Adjuvant

\section{INTRODUCTION}

Recently ionic liquids (ILs) have gained attention because of their relative environmental friendliness as well as their flexibility to be used in various settings. ILs that are generally composed of organic cations and organic/inorganic anions are a class of molten salts with melting points below $100^{\circ} \mathrm{C}$. The cations are mostly alkylated imidazole, pyrrole or pyridine derivatives, quaternary alkyl amines and alkyl phosphines. On the other hand, most representative anions of ionic liquids are halides, alkyl sulfates, fluorinated hydrocarbons, carboxylic acids or amino acids $[1,2]$. Ionic liquids are nonvolatile, nonflammable and recyclable chemical components. They possess several distinct characteristics such as excellent solvating power, good thermal stability, and tunability by using appropriate cations and anions [3,4,5]. Moreover, the physical and chemical properties, such as solubility, polarity, viscosity and acidity, are amenable to modification of the cations and anions. Due to this flexibility, ILs have been applied in certain processes such as catalytic reactions, desulfurization, hydrogenation, and electrochemistry [6-15]. All these useful properties have led to the consideration of ionic liquids as suitable candidates for chemical syntheses.

Although Paul Walden reported the first IL (ethylammonium nitrate) in 1914, the ILs have emerged as a critical research field only during the past two decades $[16,17,18]$. Based on the cation segment, ILs are broadly classified into four types: 1) alkylammonium-, 2) dialkylimidazolium-, 3) phosphonium- and 4) N-alkylpyridinium-based ILs. Ethylammonium nitrate $\left[\mathrm{EtNH}_{3}\right]\left[\mathrm{NO}_{3}\right]\left(\right.$ m.p. $12{ }^{\circ} \mathrm{C}$ ), the first discovered IL in 1914, is a room

Temperature IL [16].

Corresponding Author: Mohammad Uddin, College of Pharmacy, Larkin University, Miami, FL, USA; E-mail: muddin@ularkin.org 
With the advent of binary ionic liquids that comprise of mixtures of aluminum chloride and $\mathrm{N}$ alkylpyridinium or 1,3-dialkylimidazolium chloride, a great interest grew in the scientific community $[17,18]$. Generally, ILs are of two types: I) simple salts that are made of a single anion and cation, and II) binary ionic liquids that are salts in equilibrium. For example, $\left[\mathrm{EtNH}_{3}\right]\left[\mathrm{NO}_{3}\right]$ is a simple salt. On the other hand, a binary ionic liquid system composed of mixtures of aluminum chloride and 1,3dialkylimidazolium chlorides contains several different ionic species, and their melting points and properties depend upon the mole fractions of aluminum chloride and 1,3-dialkylimidazolium chloride present [16].

One of the unique properties of ILs are that they can be reused. Several researchers have investigated the process to recover and recycle ILs in the past few decades. The recovery and recycling procedures of ILs include extraction, membrane separation, distillation, adsorption, aqueous two-phase extraction, and crystallization [19-24]. Nevertheless, distillation and extraction are most widely used. In order to separate the volatile products from ILs, vacuum distillation is usually used, and extraction is preferred for non-volatile or thermally sensitive substances. Adsorption is a common process to recover ILs from aqueous solutions. Besides these, membrane technology is also used to separate any specific IL from a mixture, where ILs are usually found in the feed side or permeate through the membrane using the osmosis process. To recover hydrophilic ILs, the aqueous two-phase system is commonly used. This method excludes the use of any volatile organic solvent. Crystallization is also another process to obtain ILs. This process is employed for recovering ionic liquids with high purity.

The preparation of ILs can be described in two steps: (1) Synthesis of the cation, where the desired cation can be synthesized either by protonation of the amine by an acid or by amine quaternization with a haloalkane with concomitant heating. (2) Exchange of the anion, in which anion metathesis is a commonly used method for the anion exchange. In fact, this procedure is preferred for the synthesis of 1,3-dialkylimidazolium cation-based ILs that are stable in water and air. This second approach requires reactions between the halide salt with the silver/sodium/potassium salts of $\mathrm{NO}_{2}^{-}, \mathrm{NO}_{3}{ }^{-}, \mathrm{BF}_{4}^{-}$, $\mathrm{SO}_{4}{ }^{2-}$, and $\mathrm{CO}_{2} \mathrm{CH}_{3}{ }^{-}$[25-27]. Anion exchange can also be accomplished by the reaction of halide salts with Lewis acids that will lead to the formation of Lewis acid-based ionic liquids. $\mathrm{AlCl}_{3}$-based salts are very common Lewis acid-based ionic liquids. In these reactions, mixing of the Lewis acid and the halide salt leads to the production of anionic moieties and is contingent on the ratio of quaternary halide salt and Lewis acid [28-30]. Based on the relative number of reactants, ILs can be acidic or basic. Molar excess of [emim] $\mathrm{Cl}$ over $\mathrm{AlCl}_{3}$ furnishes basic ILs, whereas the molar excess of $\mathrm{AlCl}_{3}$ generates an acidic ionic liquid. Neutral ILs are formed when both [emim] $\mathrm{Cl}$ and $\mathrm{AlCl}_{3}$ are present in equimolar quantities. Some other commonly used Lewis acids are $\mathrm{BCl}_{3}, \mathrm{AlEtCl}_{2}, \mathrm{InCl}_{3}$, and $\mathrm{CuCl}$ [31-34]. Another classification of ILs comprises of protic ILs (PILs) and aprotic ILs (APILs) [35]. The transfer of protons from a Brønsted acid to a Brønsted base yields PILs. Gabriel demonstrated the first PIL, ethanolammonium nitrate (EOAN), in 1888 [36]. Conventionally, PILs possess greater fluidity, enhanced conductivity, and lower melting points [37]. Moreover, byproduct formation is not associated with their synthesis, thereby making the process more convenient and less expensive [38]. To date, the only drawback demonstrated by PILs in some reports is their predisposition to form a hydrogen bond network that ultimately compromises their ionicity [39-40]. This hydrogen bonding has been confirmed by NMR, X-ray diffraction and neutron diffraction [39]. Several other ILs have been reported that include chiral ILs, double salt ILs, polymeric ILs, solvate ILs, dicationic ILs, and deep eutectic solvents [41-44]. The complete proton transfer from a Brønsted acid to Brønsted base causes the formation of ILs, however, if the proton transfer is incomplete it forms a neutral species. Apart from this, ion complexation or aggregation also results in partial proton transfer that leads to decreased ionicity of the PILs [45]. PILs have been reported to be used in different settings, including biological systems, chromatography, and as protonconducting electrolytes for polymer membrane fuel cells $[38,46,47]$. They are also used as a Brønsted acid or base in many acid-base-catalyzed organic reactions such as aldol condensation, Fischer esterification, Knoevenagel condensation, and the Diels-Alder reaction [48-51]. Due to their microwave-absorbing nature, they are a good alternative to be applied as a medium or catalyst in many microwave-assisted reactions. Some other uses of PILs are in the esterification of benzoic and salicylic acids, the dehydration of D-fructose and 
glucose, and the solvent-free synthesis of coumarins [52-55].

Indeed, plenty of ionic liquids are mixtures of different cations and anions. More than a thousand ILs have been reported including single, binary and ternary ionic liquids. By virtue of being readily customized they are applied in different settings such as solvents in organic syntheses, additives in pigments, storage media for toxic gases, and so on. By employing state-of-the-art technology that includes irradiation with microwaves (MW) and power ultrasound (US), IL synthesis has been improved significantly. These techniques can be used either alone or in combination and can result in better yields within a shorter time. More advanced methodologies that utilize efficient, solvent-less, one-pot synthetic protocols are expected to scale down expenditure associated with the production of ILs.

\section{PHYSICOCHEMICAL PROPERTIES OF IONIC LIQUIDS}

Ionic liquids have very diverse physicochemical properties which are impacted by the composition of the ionic liquid. Physical properties of ionic liquids are determined by the presence of different types of ions in the ionic liquid. The IL physicochemical properties include lattice energy, surface entropy, molar entropy, the molar enthalpy of vaporization, molar surface Gibbs energy, interstitial molar surface Gibbs energy, enthalpy, density, viscosity, and thermal stability. Physicochemical properties are extensively studied in pharmaceutical industries as they are very important for both active pharmaceutical ingredients (API) and excipients. Several properties of API and excipients, such as stability, solubility, flowability, lubricity, and disintegration, depend on the physicochemical properties. The particle size and shape of the powder excipient, as well as fundamental forces acting on particles in powders such as adhesion, friction, and gravitational forces, also depend on physicochemical properties and are considerable factors in formulation development [56]. The diverse nature of the physicochemical properties of ILs have rendered them as potential excipient candidates in formulation development. Below we have discussed some of the physical properties which are relevant to the pharmaceutical application of ionic liquids.

\section{1) Enthalpy}

Enthalpy is one of the most fundamental thermodynamic properties of ILs. Although the measurement of the enthalpy of ILs is at a rudimentary stage, it is possible to substantiate the force fields that are employed in computational studies of the behavior of ILs. These validated force fields serve as a consistent measure for the predictions of physical and chemical properties [57].

Using different solvents and with the help of an isothermal titration calorimeter at $25^{\circ} \mathrm{C}$, the solution enthalpies of some ILs based on imidazolium cations have been measured. Several reports are available that demonstrated the measurement of the enthalpies of vaporization, $\Delta$ vapHT, at temperature $\mathrm{T}$, for different ILs by using both experimental and theoretical methods [58-59]. Fumino et al. demonstrated a linear relationship between published $\Delta \mathrm{vapH}$ values and their measured vibrational frequencies by measuring the far infrared (FIR) spectra of 1- ethyl-3-methylimidazoliumbased ILs and a variety of anions [60]. By using tunable vacuum ultraviolet photoionization, Chambreau et al. reported $\Delta \mathrm{vapH} 298$ values of several ILs [61]. Meanwhile, Wang et al. estimated $\Delta$ vapHT values for a group of imidazolium- and pyrrolidinium-based ILs over a range of temperatures by using UV absorption spectra [62]. Recently, Deyko et al. determined $\Delta \mathrm{vapH} 298$ of seven ionic liquids by means of temperatureprogrammed desorption using line of sight mass spectrometry. Their ILs included four imidazoliums, a pyridinium, a phosphonium, and an isouronium [63].

\section{2) Multi-phases}

A group of researchers led by Domanska studied phase equilibrium data for ILs in water and other organic solvents where they examined phase equilibria from melting points of ILs to boiling points of organic solvents. Different GEx models were employed to determine the (solid+liquid) and (liquid+liquid) phase equilibria curves [64]. Mostly the differential scanning calorimetry (DSC) technique was used to study phase transitions of materials. In this method, the same temperature $(\Delta T$ $=\mathrm{Ts}-\mathrm{Tr}=0)$ is applied to both the sample and the reference substance and any heat transfer between the sample and reference substance is recorded against the temperature [65]. Usually alumina $\left(\mathrm{Al}_{2} \mathrm{O}_{3}\right)$ and silicon carbide $(\mathrm{SiC})$ are used as the reference substances in DSC technique and these 
substances are stable in terms of phase change over a broad range of temperatures. The phase change is determined by plotting heat flow against temperature where divergence from the baseline of the DSC trace is indicative of a phase change. A phenomenon called the glass-transition temperature (Tg) of ILs refers to the cohesive energy within its salt. Repulsive Pauli forces result in a drop in $\mathrm{Tg}$, while attractive Coulomb and van der Waals interactions elevate this parameter. An alteration in cations or anions can decrease the $\mathrm{Tq}$, thereby lowering the cohesive energy of ILs. With an increase in temperature, there will be a decline in viscosity and consequently more fragility will be observed for ILs [66].

\section{3) Thermal stability}

Generally, the ILs exhibit thermal stability at or above $400{ }^{\circ} \mathrm{C}$, and this stability is mostly contingent on the nature of the anions [67]. A decent correlation has been reported between the thermal stability of ILs with anion-coordinating nature, hydrophilicity, and nucleophilicity [68]. For example, when there is an increase in the hydrophilicity of anions, thermal decomposition decreases. Compared to pyridinium, tetra alkyl ammonium, and piperidinium ILs, imidazolium ILs are conventionally more stable [69]. Apart from the IL structure, other factors like contaminants (such as water and halides) and experimental conditions (such as sample mass, heating rate, atmosphere type, atmosphere flowing rate, sample pan material, and instrument type) have also been reported to impact the thermal stability of ILs [70, 71]. The mechanism of IL decomposition is another aspect to consider. Several robust analysis methods such as thermogravimetric analysis coupled with mass spectrometry (TGA-MS), thermal desorption mass spectroscopy (TD-MS), and pyrolysis-gas chromatography (pyrolysis-GC), have been utilized to find out the decomposition products as well as to reveal the decomposition mechanisms of ILs. Commonly substituent reactions are involved in the decomposition of ILs [72-74]. When anions attack the cations, $\mathrm{C}-\mathrm{N}$ bonds undergo cleavage, along with $\mathrm{S}_{\mathrm{N}} 2$ and $\mathrm{S}_{\mathrm{N}} 1$ pathways [72]. In the presence of non-coordinative anions, ILs follow elimination or rearrangement reactions. Quantum chemical calculations have also been shown to furnish additional information on the decomposition mechanisms [75]. The reports on the thermal stability of ILs include data that were measured at varying conditions making thermal stability data from different publications incomparable. Moreover, nearly all studies focused on traditional ILs, such as [BMIM] $\left[\mathrm{PF}_{6}\right],[\mathrm{BMIM}]\left[\mathrm{Tf}_{2} \mathrm{~N}\right],[\mathrm{BMIM}][\mathrm{Cl}]$, and reports are scanty on long-term stability [76]. $T_{\text {onset }}$ usually marks thermal stability and as decomposition occurs, it is calculated on the temperature curve from the intersection of the baseline weight and the tangent of the weight dependence. Very often, before reaching the onset temperature ILs begin to decompose. Del Sesto et al. showed a substantial decomposition of ILs [bmpy][Tf $\left.\mathrm{T}_{2} \mathrm{~N}\right]$ and $[\mathrm{BMIM}]\left[\mathrm{Tf}_{2} \mathrm{~N}\right]$ at $250{ }^{\circ} \mathrm{C}$ negating the regular decomposition temperature of about $400{ }^{\circ} \mathrm{C}$ [77]. Hence, a new parameter, $T_{0.01 / x}$, was recommended. $T_{0.01 / x}$ denotes the temperature at which the decomposition of ILs reaches $1 \%$ for a given time $x$. But it did not solve the problem since a huge discrepancy was still observed. For example, the difference between $T_{\text {onset }}$ and $T_{0.01 / 10 \mathrm{~h}}$ (the temperature at which $1 \%$ mass loss occurs in $10 \mathrm{~h}$ ) was around $200{ }^{\circ} \mathrm{C}$ [78]. Nevertheless, there are several conflicting data on the thermal stability of various ILs and therefore, the high decomposition temperature of ILs should be calculated from fast thermogravimetric analysis (TGA) that measures the loss of a sample with respect to temperature in a set environment.

\section{4) Density}

Commonly, the density of ILs is greater than that of water. An increase in pressure results in an increase in density while an increase in temperature leads to a decrease in density. Largely the component cations and anions are responsible for the magnitude of the density of the ILs. Generally, the density of ILs decreases with an increase in the length of the organic cation and the density decreases with an increase in length of the anion group. When the cation is kept constant, the order of density of ILs follows the order: $\left[\mathrm{BF}_{4}^{+}\right]^{-}<\left[\mathrm{OTf}^{+}\right]^{-}<\left[\mathrm{PF}_{6}^{+}\right]^{-}<$ $\left[\mathrm{NTf}_{2}{ }^{+}\right]^{-}[38]$.

\section{5) Viscosity}

Viscosity is very critical for ILs and it depends on van der Waals interactions and hydrogen bonding [79]. The viscosity of ILs controls the rate of diffusion inversely. The anionic structure plays an important role in the viscosity of ILs. Compared to ILs with high viscosity, ions move more freely in less viscous liquids. As a rule of thumb, higher viscosities are preferred for lubrication or in supported membrane separation processes and lower 
viscosities are required to increase the rate of mass transfer in solvents. Usually the viscosities of ILs are greater than those of commonly used solvents. The viscosities of ILs are variable for different cations and anions. The cation of an IL having a larger alkyl chain has a higher viscosity while ILs possessing very symmetric or almost spherical anions are comparatively more viscous. One explanation for this effect is due to the formation of weak hydrogen bonds between anions and cations. The ILs having $\left[\mathrm{NTf}_{2}\right]$ - anions demonstrate superior charge delocalization as well as chain flexibility that leads to a decrease in viscosity compared to other anionbased ILs. With the same cation and variable anions, the viscosities of ILs follow this order: $\left[\mathrm{CH}_{3} \mathrm{COO}\right]^{-}>$ $\left[\mathrm{PF}_{6}\right]^{-}>\left[\mathrm{C}_{1} \mathrm{SO}_{4}\right]^{-}>\left[\mathrm{C}_{2} \mathrm{SO}_{4}\right]^{-}>\left[\mathrm{BF}_{4}\right]^{-}>[\mathrm{OTf}]^{-}>$ $\left[\mathrm{NTf}_{2}\right]^{-}[80]$.

\section{6) Melting point}

Melting point is perhaps the most essential property of ILs that relies on the structure and composition of ILs. The melting points of ILs are determined by the presence of both anions and cations. ILs are ionic compounds which exhibit comparatively lower melting points. On the other hand, ionic compounds with high coulombic force have strong interactions between the ions and have high melting points. For example, the melting point of sodium chloride is $801^{\circ} \mathrm{C}$. Its cations and anions are small, spherical and of similar size and their packing is well defined, which results in very powerful Coulomb forces [81]. Normally a cation with low symmetry in an ionic liquid exhibits a lower melting point than one with high symmetry. Additionally, a decent charge distribution and weak intermolecular interactions in the cation support a low melting point of an IL. Another example is $[\mathrm{EMIM}] \mathrm{Cl} / \mathrm{AlCl}_{3}$, a chloroaluminate IL that shows interesting trends in its melting point. The composition of [EMIM] $\mathrm{Cl} / \mathrm{AlCl}_{3}$ greatly affects its melting point [82]. By combining two species, a suitable IL can be developed that will have a low melting point. This is crucial for designing ILs suitable for certain applications where low melting point is required.

\section{7) Mutual solubility}

The phase behavior, or the mutual solubility, of ionic liquids with other solvents is another important aspect to consider. This is determined by the cation, the substituents on the cation, the anion, and the solvents. The impact of the anion on the phase behavior of imidazolium-based ionic liquids with alcohol was reported by Crosthwaite et al. With alcohol, the mutual solubility of imidazolium-based ILs follows the order: $[\mathrm{DCA}]^{-}>[\mathrm{OTf}]^{-}>\left[\mathrm{NTf}_{2}\right]^{-}>$ $\left[\mathrm{BF}_{4}\right]^{-}>\left[\mathrm{PF}_{6}\right]^{-}[83]$. Heintz et al. reported that with an increase in the alkyl chain length of the alcohols, the mutual solubility of the IL and alcohol decreases [84]. Crosthwaite et al. demonstrated that the increase in alkyl branching results in a greater dissolution of the ionic liquid compared with the corresponding linear alcohol. They proposed that the phenomenon was due to the diminished infinite dilution activity coefficient of the branched alcohols [83]. The van der Waals interactions are known to increase between the alkyl chain on the cation and the alkyl chain on the alcohol when there is an increase in the chain length on the cation, and this event leads to the augmentation of the mutual solubility of ILs with alcohols [85]. Also, the mutual solubility of ILs comprising of water and imidazolium decreases with an increase in the alkyl chain length on this cation [86]. This happens due to the change in the cohesive energy of these ILs impacted by an escalation of the van der Waals forces with the alkyl chain length.

\section{8) Conductivity}

The ionic conductivity largely depends on the existing charge and two factors, namely, molecular weight and the size of the ion. The relationship between chemical structures and transport properties of ILs has not been extensively studied yet. However, based on the reports so far, the extent of conductivity of ILs is usually moderate and it lies in between aqueous electrolytes and water. The diffusion rate of ions in the ILs influences the ionic conductivity. The ions can move faster when the diffusion rate is high, and this allows the charges to get transported through the liquid rapidly. The NMR data has shown that both [BMIM] and [BPy] cations diffuse at a similar rate as $\left[\mathrm{BF}_{4}\right]^{-}$. Considering the sum of cationic and anionic diffusion coefficients, ionic liquids follow the order: [EMIM] $\left[\mathrm{Tf}_{2} \mathrm{~N}\right]>$ $[\mathrm{EMIM}]\left[\mathrm{BF}^{4}\right]>[\mathrm{BP}]\left[\mathrm{Tf}_{2} \mathrm{~N}\right]>[\mathrm{BP}]\left[\mathrm{BF}_{4}\right]$. Indeed, not only viscosity but also ionic size and ion pairs impact the conductivity of ILs [87].

\section{POTENTIAL USE OF IONIC LIQUIDS IN PHARMACEUTICAL FORMULATIONS}

Due to their malleable physical and chemical properties, ionic liquids are potential candidates to be used as excipients. Ionic liquids can be used in drug 
dosage forms to increase the solubility, drug permeability and stability, to provide charge on drug formulations, and for site-specific or organ-targeted delivery. Ionic liquids exhibit better permeability and bioavailability when acidic and basic drugs were used [88]. Since they can play multiple roles, using ionic liquids alone can replace several excipients in drug formulations which can make formulations more efficient and less costly. Below we have discussed the potential applications of ionic liquids for different purposes such as stabilizers, permeability enhancers, and solubility enhancers. The use of different types of ILs as excipients in small molecule drugs are shown in Table 1.

\section{1) Stabilizer}

ILs have been employed as potential protein stabilizers and this property might play a central role to address the stability problems of numerous biopharmaceuticals. Biologics are crucial in the management of infections, auto-immune diseases, cancers, and other difficult conditions [89].

Some imidazolium ILs exhibited protein refolding. For example, Yamaguchi et al. showed the refolding property of hydrophobic imidazolium cations where $[\mathrm{BMIM}][\mathrm{Cl}]$ displayed the maximum refolding capacity [90]. Contrastingly, the denaturing property of ILs has also been reported. Kumar et al. investigated the impact of three imidazolium ILs - [BMIM][Cl], [BMIM][Br], and [BMIM][I] on the thermal stability of stem bromelain. [BMIM][I] emerged as the most denaturing and the order of thermal stability was $[\mathrm{BMIM}][\mathrm{Cl}]>[\mathrm{BMIM}][\mathrm{Br}]>[\mathrm{BMIM}][\mathrm{I}]$ [91]. Takekiyo et al. demonstrated that 1-butyl-3methylimidazolium thiocyanate ([BMIM][SCN]) and ethylammonium nitrate (EAN) significantly reduced the activity of cytochrome $\mathrm{C}$ (cyt $\mathrm{C}$ ) and lysozyme and elicited unfolding. However, they regained their activities and refolding was imminent with the removal of the ILs and this observation supported the reversible denaturant effects of imidazolium ILs [92]. Buchfink et al. studied the effect of the anion on the ability of EMIM-ILs to stimulate refolding of recombinant plasminogen activator $(\mathrm{rPa})$ and stability of lysozyme. They found that the ability of the anion to promote refolding of $\mathrm{rPa}$ while coupled to EMIM followed the order of $\left[\mathrm{Cl}^{-}\right]>\left[\mathrm{MDEGSO}_{4}^{-}\right]>\left[\mathrm{EtSO}_{4}^{-}\right]>\left[\mathrm{Ac}^{-}\right]>\left[\mathrm{Tos}^{-}\right]>$ $\left[\mathrm{Et}_{2} \mathrm{PO}_{4}^{-}\right]>\approx\left[\mathrm{HexSO}_{4}{ }^{-}\right]$. The order of the melting temperature $(\mathrm{Tm})$ of lysozyme was $\left[\mathrm{Cl}^{-}\right]>\left[\mathrm{EtSO}_{4}^{-}\right]$ $\approx\left[\mathrm{MDEGSO}_{4}^{-}\right]>\left[\mathrm{Et}_{2} \mathrm{PO}_{4}^{-}\right]>\left[\mathrm{Ac}^{-}\right] \approx\left[\mathrm{Tos}^{-}\right]>$
[HexSO $4_{4}^{-}$] [93]. Attri et al. has reported the thermal stability of $\alpha$-chymotrypsinogen (CT) in five ILs based on phosphonium, ammonium, and imidazolium salts. The imidazolium ILs, namely, 1benzyl-3-methylimidazolium chloride ([BzMIM][Cl]) and 1-benzyl-3-methylimidazolium tetrafluoroborate ([BzMIM][BF4]), enhanced the thermal stability $\left(\mathrm{T}_{\mathrm{m}}\right)$ of $\mathrm{CT}$ to a small extent. Triethyl ammonium acetate (TEAA) showed the highest stabilizing effect on CT with an increase in $\mathrm{T}_{\mathrm{m}}$ from 42 to $65^{\circ} \mathrm{C}$ [94]. Lange et al. evaluated the stability of lysozyme by using [BMIM][Cl], [OHEMIM][Cl], and [OH-PMIM][Cl] and reported a marked decrease in the $T_{m}$ of lysozyme with an increase in the alkyl chain length of the cation. Moreover, they confirmed that an increase in the alkyl chain length and hydrophobicity of the cation moiety leads to a decrease in the conformational stability of lysozyme [95].

Fujita et al. reported a greater long-term stability of cyt $\mathrm{C}$ after dissolution in a solution of $80 \% \mathrm{w} / \mathrm{v}$ [Chol][DHP] [96]. Weaver et al. showed inhibition of lysozyme and recombinant human interleukin-2 (rHIL-2) denaturation by [Chol][DHP]. Furthermore, they also demonstrated the formation of irreversible aggregates after denaturation of rHIL2 and lysozyme that were formulated with [Chol][DHP] [97]. Mazid et al. showed a prolongation of the biological activity of EGFR (Anti-epidermal growth factor) $\mathrm{mAb}$ (monoclonal antibody) in $50 \% \mathrm{w} / \mathrm{v}$ concentrations of buffered [Chol][DHP]. The stability was also enhanced in the presence of proteinase $\mathrm{K}$ and $50 \% \mathrm{w} / \mathrm{v}$ buffered [Chol][DHP]. They proposed that buffered [Chol][DHP] stabilized the EGFR mAb alphahelices [98]. Rodrigues et al. investigated the stability of lysozyme in different choline-based ILs, namely, choline dihydrogen phosphate [Chol][DHP], choline dimethyl phosphate [Chol][DMP], choline trimethylacetate [Chol][TMA], choline trifluoromethane sulfonate [Chol][TFMS], choline lactate [Chol][Lac], choline propionate [Chol][Prop], choline bis(trifluoromethylsulfonyl)amide $\quad[\mathrm{Chol}]\left[\mathrm{TF}_{2} \mathrm{~N}\right]$, choline hexanoate [Chol][Hex], and choline chloride $[\mathrm{Chol}][\mathrm{Cl}]$. According to their study, [Chol][DHP] and $[\mathrm{Chol}]\left[\mathrm{TF}_{2} \mathrm{~N}\right]$ resulted in the highest stabilization and destabilization, respectively. The order of stability was: $\left[\mathrm{DHP}^{-}\right]>\left[\mathrm{DMP}^{-}\right]>\left[\mathrm{Lac}^{-}\right]>$ $\left[\mathrm{Cl}^{-}\right]>>\left[\right.$Prop $\left.^{-}\right]>\left[\right.$TFMS $\left.^{-}\right] \sim\left[\mathrm{TMA}^{-}\right]>\left[\mathrm{Hex}^{-}\right]>$ $\left[\mathrm{TF}_{2} \mathrm{~N}^{-}\right][99]$. 
Meanwhile, Bisht et al. investigated some choline ILs involving carboxylate and phosphate anions as a potential media for cyt C. Of all the ILs, the highest catalytic activity of cyt $\mathrm{C}$ was observed with choline glutarate $([\mathrm{Chol}][\mathrm{Glu}])$ at $50 \% \mathrm{w} / \mathrm{v}$ of the IL [100]. Recently, Tarannum et al. investigated the effect of four choline-based ILs (choline serinate, threoninate, lysinate, and phenylalaninate) on the structural stability of collagen and confirmed the destabilization that resulted from the competing hydrogen bonds between the ILs and $\mathrm{OH}$ groups on the collagen [101].

\section{2) Permeability enhancer}

ILs were employed in the delivery of different APIs such as solvents, nanoparticles, functionalizing agents, and dispersing agents. These led to improved transdermal permeation of the APIs. Kandasamy et al. showed that ammonium acetate-based ILs facilitate the formulation of IL-in-oil microemulsions that result in better solubilization [102]. Yoshiura et al. advanced this finding by demonstrating an improvement in microemulsion size by IL incorporation, thereby augmenting transdermal permeation [103].

The IL-based formulations displayed great potential to enhance the permeability of poorly permeable drugs. An IL composed of octanoic or isostearic acid and diisopropanolamine or triisopropanolamine promoted skin permeability without causing any skin impairment [104]. Another IL comprised of proline ethylester-ibuprofenate demonstrated improved transdermal permeation [105]. A morpholinium-based IL has been reported to increase the transdermal transport of diltiazem, a calcium channel blocker [106]. Cholinium geranate was also shown as a useful permeation enhancer [107]. Moreover, another IL of lidocainium docusate showed enhanced membrane permeability by virtue of forming ionic associates. Apart from these, improved skin penetration of a model substance in vitro was reported by oil-in-water and water-in-oil emulsions with $\left[\mathrm{C}_{6} \mathrm{MIM}\right][\mathrm{Cl}]$ or $\left[\mathrm{C}_{4} \mathrm{MIM}\right]\left[\mathrm{PF}_{6}\right]$ [108]. Some IL-containing nanodispersions that showed improved skin penetration were recommended to be used with hydrophilic macromolecules for transcutaneous vaccinations [109].

\section{3) Solubility enhancer}

To be functional, a drug must reach the site of action from the site of administration, which is defined as drug absorption.

Lipophilic drugs have solubility problems in the body fluid; therefore, converting these types of drugs into lipophilic salts or ionic liquids can increase the water solubility. On the other hand, the salt formation or ionic liquid formation of these drugs may reduce the solubility of the lipophilic salt drug in lipids. However, it was found that lipophilic salt ionic liquid forms can also have higher lipid solubility. Williams et al. compared the lipid formulation candidacy of the lipophilic salts of Biopharmaceutical Classification System (BCS) Class I amlodipine and BCS Class III fexofenadine, ranitidine, and metformin with the existing commercial salts. For this purpose, lipophilic salts were prepared from lipophilic anions and commercial $\mathrm{HCl}$ or besylate salt forms, and analyzed by $1 \mathrm{H}-\mathrm{NMR}$, differential scanning calorimetry (DSC), and hot-stage microscopy. X-ray diffraction and polarized light microscopy were also used to confirm the salt's physical form. Results showed that all lipophilic salt forms were substantially more lipid-soluble (typically $>10$-fold) when compared to commercial salts and had greater drug loadings in lipid formulations. In vitro tests showed that lipophilic salts or ionic liquids solubilized in a lipid formulation resulted in dispersion behavior that was at least as rapid as the dissolution rates of conventional salts. This study confirmed the applicability of forming lipophilic salts or ionic liquids of BCS Class I and III drugs to promote the utility of lipid-based delivery systems [110].

Sahbez et al. transformed weakly acidic poorly water-soluble drugs (PWSD) into ionic liquids (ILs) to enhance solubility. For this purpose, ionic liquid forms of drugs were prepared directly from tolfenamic acid (Tolf), meclofenamic acid, diclofenac, and ibuprofen by pairing them with lipophilic counterions. The drug-ILs were obtained as liquids or low melting solids and were significantly more soluble (either completely miscible or highly soluble) in lipid-based, selfemulsifying drug delivery systems (SEDDS) when compared to the equivalent free acid. They also conducted an in vivo study of a SEDDS lipid solution formulation of Tolf didecyldimethylammonium salt and the same formulation of Tolf free acid at a low dose (18 $\mathrm{mg} / \mathrm{kg}$ ). The results showed similar absorption 
profiles and overall exposure in both cases. They demonstrated that the free acid administration was only possible as a suspension in the SEDDS formulation or as an aqueous suspension. These resulted in markedly different plasma profiles with prolonged exposure and reduced Cmax for the IL formulations. The advantage of isolating a weakly acidic drug as an IL is that it allows formulation as a solution SEDDS rather than a lipid suspension, and in some cases may provide a means of slowing or sustaining absorption. This study further confirmed that weakly basic PWSDs transformed into highly lipophilic ILs increases the solubility significantly [111].

Sahbaz et al. also further investigated the enhancement of solubility of weakly basic, poorly water-soluble drugs (PWSDs) itraconazole, cinnarizine, and halofantrine by converting them to ionic liquids. Their conversion into lipophilic ionic liquids facilitates incorporation into lipid-based formulations and integration into lipid absorption pathways. Low melting point, completely miscible and highly soluble drug-ionic liquids (active pharmaceutical ingredient - ionic liquid API-IL) were prepared via metathesis reactions of the hydrochloride salt of the PWSDs with a range of lipophilic counterions. These API-ILs are selfemulsifying drug delivery systems (SEDDS) comprising of mixtures of long or medium chain glycerides, surfactants such as Kolliphor-EL and cosolvents such as ethanol. They are readily incorporated into the colloids formed in intestinal fluids during lipid digestion. In an in vivo study, itraconazole docusate or cinnarizine decylsulfate API-ILs were subsequently dissolved in long chain lipid SEDDS at high concentrations and orally administered to rats. The results were compared to control formulations based on the SEDDS formulations containing the same concentrations of drug as the free base. In comparison to the suspension (or physical mixture for itraconazole) formulations at the same dose, both the drugs displayed an increased plasma exposure for the APIIL-containing formulations (2-fold for cinnarizine and 20-fold for itraconazole). The API-ILs also provided advantages in dose uniformity, capsule filling, and stability compared to similar suspension formulations. This study lends support to the fact that the lipophilic ionic liquids facilitate the loading of dissolved drugs in lipid-based formulations which consequently promotes the exposure of poorly water-soluble drugs after oral administration [112].

\section{POTENTIAL USE OF IONIC LIQUIDS IN VACCINES}

Unlike a drug's therapeutic action in cells for curative purposes, a vaccine works to stimulate the immune system of the body. Vaccines work by either stimulating antibody-producing cells such as B cells or the killer cells such as T cells. Vaccines can be administered in different routes, such as oral and intramuscular, with different forms such as suspension, nanoparticle or microparticle. Ionic liquids can be used potentially in different stages of vaccine mechanisms such as penetration enhancers, vaccine stabilizers, or adjuvants. The use of different types of ILs in vaccines has been shown in Table 1.

\section{1) Penetration enhancer:}

Several vaccines are administered via subcutaneous and transdermal routes. In such cases a penetrating agent enhances the effects of vaccines. ILs have potential to be used as penetration enhancers. A novel IL-mediated transcutaneous vaccine formulation was reported by Araki et al. where they employed a solid-in-oil (S/O) nano-dispersion of antigen coated with surfactants. The skin permeability of the model antigen ovalbumin (OVA) was significantly improved due to the incorporation of the IL $\left[\mathrm{C}_{12} \mathrm{mim}\right]\left[\mathrm{Tf}_{2} \mathrm{~N}\right]$ (1-dodecyl-3-methyl imidazolium bis(trifluoromethyl sulfonyl) amide) in the formulation. Moreover, the IL-mediated S/O nanodispersion exhibited elevated levels of OVAspecific serum IgG compared to both PBS control and S/O nanodispersions without IL. These outcomes evidenced that ILs might boost skin penetration in transcutaneous vaccinations for hydrophilic macromolecules. It also showed that the ILs are biosafe and biocompatible [113].

\section{2) Vaccine stabilizer:}

Stabilizers help the vaccine remain unchanged when the vaccine is exposed to heat, light, acidity, or humidity. Stabilizers also help the vaccine antigens, such as proteins, peptides, enzymes, inactivated bacteria, viruses, and virus-like-particles, to stay in their original forms. ILs can also be applied to stabilize vaccines. ILs can enhance stabilization of proteins, enzymes, and viruses [114-115]. Proteins are highly sensitive to changes in their vicinity induced by temperature, $\mathrm{pH}$, humidity, salt concentration, and any mechanical stress applied during manufacturing [89]. As they are exposed to these stressors, they undergo gradual changes in 
structure, and form protein aggregates over time [116]. In addition, the poor stability of proteins and enzymes might result in loss of function and activity, significantly limiting their use in biological processes and as biopharmaceuticals.

\section{3) Adjuvants}

An adjuvant is an ingredient used in vaccines that helps create a stronger immune response when administered. Ionic liquids can potentially be used as adjuvants in vaccine formulations. Conventional suspension vaccines exhibit problems of separation of two phases formed by the dissolution of two polymers (or antigens), a polymer and a salt, or two salts in water separation processes [117-118].

Table 1: Use of different types of ionic liquids in small molecule drugs and vaccines:

\begin{tabular}{|c|c|c|c|c|}
\hline Types of Ionic liquids & Purpose of use & Type of drug & Dosage form & References \\
\hline $\begin{array}{l}\text { 1. Lidocanium docusate } \\
\text { 2. [C4mim][Cl] (1-Butyl-3- } \\
\text { methylimidazolium chloride) } \\
\text { 3. [BMIM][Tf } 2 \text { N](1-Butyl-3- } \\
\text { methylimidazolium } \\
\text { bis(trifluoromethylsulfonyl)imide) }\end{array}$ & Permeability & $\begin{array}{l}\text { Small molecule } \\
\text { drug and vaccine }\end{array}$ & Transdermal & $\begin{array}{l}\text { Smith et al } \\
{[149],} \\
\text { Cromie et al } \\
{[150]}\end{array}$ \\
\hline $\begin{array}{l}\text { 1. }[\mathrm{C} 4 \mathrm{mim}][\mathrm{N}(\mathrm{CN}) 2] \\
\text { (1-butyl-3-methylimidazolium } \\
\text { dicyanamide) } \\
\text { 2. } \quad[\mathrm{C} 4 \mathrm{mim}][\mathrm{Cl}] \\
\text { (1-butyl-3-methylimidazolium chloride) } \\
\text { 3. } \quad[\mathrm{C} 2 \mathrm{mim}][\mathrm{N}(\mathrm{CN}) 2] \\
\text { (1-ethyl-3-methylimidazolium } \\
\text { dicyanamide) } \\
4 \quad[\mathrm{C} 4 \mathrm{mim}][\mathrm{Tos}] \\
\text { (1-butyl-3-methylimidazolium tosylate) } \\
\text { 5. Choline-tryptophan }\end{array}$ & Solubility & $\begin{array}{l}\text { Small molecule } \\
\text { drug }\end{array}$ & $\begin{array}{l}\text { Emulsion, } \\
\text { suspension }\end{array}$ & $\begin{array}{l}\text { Cláudio et al } \\
\text { [146], } \\
\text { Alawi et al } \\
\text { [147] }\end{array}$ \\
\hline $\begin{array}{l}\text { 1. } \text { BDMImBF}_{4} \\
\text { (1-butyl-2,3-dimethylimidazolium } \\
\text { tetrafluoroborate) } \\
\text { 2. AAImBF } 4 \\
\text { (1,3-diallyl imidazolium } \\
\text { tetrafluoroborate) } \\
\text { 3. AEImBF4 } \\
\text { (1-allyl-3-ethylimidazolium } \\
\text { tetrafluoroborate) }\end{array}$ & Adjuvant & Vaccine & Suspension & An et al [151] \\
\hline $\begin{array}{l}\text { 1. DABCO }(1,4- \\
\text { diazabicyclo[2.2.2]octane) } \\
\text { 2. Choline-geranate } \\
\text { 3. Tetraalkylphosphonium-hexanoate }\end{array}$ & $\begin{array}{l}\text { Penetration } \\
\text { enhancer }\end{array}$ & Vaccine & Transdermal & $\begin{array}{l}\text { Monti et al } \\
{[106],} \\
\text { Zakrewsky et } \\
\text { al }[107]\end{array}$ \\
\hline $\begin{array}{l}\text { 1. TEAA } \\
\text { (triethyl ammonium acetate } \\
\text { 2. TEAP } \\
\text { (triethyl ammonium phosphate) } \\
\text { 3. Cholinium dihydrogen citrate } \\
\text { 4. Cholinium Glutarate }\end{array}$ & $\begin{array}{l}\text { Stability } \\
\text { enhancer }\end{array}$ & Vaccine & Suspension & $\begin{array}{l}\text { Attri et al [94], } \\
\text { Bisht et al } \\
{[148]}\end{array}$ \\
\hline
\end{tabular}


However, ionic liquids can be a good alternative to enhance the separation due to the high solubility of most ILs in water at room temperature. The use of small quantities of ILs as adjuvants in polymer-based aqueous two-phase systems (ATPS) appears as an alternative to overcome these difficulties [119]. Several studies have attempted to study the ionic liquid as an adjuvant. Pereira et al. studied the Ltryptophan partition in aqueous two-phase systems composed of polyethylene glycol (PEG) with a molecular weight of $600 \mathrm{~g} \cdot \mathrm{mol}-1$ (PEG 600) and sodium sulfate $\left(\mathrm{Na}_{2} \mathrm{SO}_{4}\right)$ with the addition of $5 \%$ of imidazolium-based ionic liquid as an adjuvant. It was found that the partition coefficient $(\mathrm{K})$ of Ltryptophan is mainly dependent on the IL nature and on the IL partition to the polymer-rich phase. The addition of only $5 \%$ of imidazolium-based IL provides enhanced extraction efficiencies $(\mathrm{EE} \%)$, varying between $80 \%$ and $99 \%$, when compared to the ATPS with no IL added [118]. A similar study with different PEG (PEG 300) with higher concentration of ILs was conducted by Almeida et al. ILs were also used in concentrations ranging between $5-10 \%$ as adjuvants in ATPS constituted by PEG 300 and $\mathrm{Na}_{2} \mathrm{SO}_{4}$ for the extraction of gallic, vanillic and syringic acids [120]. Ferreira used ILs as adjuvants with ATPS composed of PEG 400 and potassium citrate buffer at $\mathrm{pH} 7.0$ to extract Immunoglobulin $\mathrm{G}$ ( $\mathrm{IgG}$ ) from rabbit serum [121]. The EE of IgG was noted when $5 \%$ IL was used. Aziz et al. used ATPS formed by PEGs of different molecular weights and potassium phosphate, potassium citrate and sodium acetate to extract $\beta$ mannanase. It was found that only $3 \%$ of $\left[\mathrm{C}_{4} \mathrm{mim}\right]\left[\mathrm{BF}_{4}\right]$ (1-butyl-3-methylimidazolium tetrafluoroborate) in the ATPS formulation enhances the $\beta$-mannanase partition to the salt-rich phase [122]. Another study was conducted by De Souza et al. using two PEG polymers. The partition of two dyes in ATPS composed of PEG 1500 and 8000 and a phosphate buffer at $\mathrm{pH} 7.0$ with $5 \%$ of ILs as adjuvants shows that ILs have a minor effect upon the ATPS formation, and that the partition coefficient values obtained in the systems with ILs are lower than in systems without them [123]. The extraction of lipase produced by submerged fermentation by Bacillus sp. ITP-001 using imidazolium-based ILs as adjuvants (5\%) in ATPS composed of several different PEGs (1500, 4000, 6000 and 8000) and potassium phosphate buffer at pH 7 was also studied [124]. Catarina et al. also studied a variety of ILs as adjuvants (chloride-based combined with cholinium, imidazolium, pyrrolidinium, piperidinium, tetralkylammonium and tetralkylphosphonium cations) with ATPS formed by polyethylene glycol (PEG 400) and a weak salting-out salt $\left(\left(\mathrm{NH}_{4}\right)_{2} \mathrm{SO}_{4}\right)$ [125]. The respective phase diagrams were determined, and the systems extraction performance for a wide range of biomolecules (phenolic compounds, alkaloids and amino acids) were investigated. These results clearly indicate that the incorporation of ILs as adjuvants in polymer-salt ATPS leads to the modulation of biomolecule partitioning.

\section{CYTOTOXICITY OF IONIC LIQUIDS}

Although ionic liquids emerged as a potential replacement for traditional volatile and harmful organic solvents, studies have shown that large amounts of ionic liquids can be toxic and less biodegradable. Therefore, the use of ILs in the human body as drug components warrants extensive cytotoxic evaluation. The flexibility of ILs has been the most important factor for cytotoxicity studies. Indeed, it is very appealing to develop therapeutic agents with tailored anticancer activity and diminished toxicity toward the normal counterparts. A significant number of evidences have demonstrated the anticancer properties of ILs. The cancers targeted include colon cancer, breast cancer, brain cancer, histiocytic lymphoma, cervical cancer, lung cancer, and squamous cancer [126-131]. Apart from these, they have been successfully applied in other cells, namely, mouse, rat, Chinese hamster, and human fibroblasts [132-135].

Although the preliminary studies claimed the cations of ILs to be the principal determinant of toxicity, it is now obvious that their toxicities include both the cations and anions [136]. A number of factors control the extent of toxicity and the most prominent ones are the length of the alkyl side chain and the branching and hydrophobicity of the ion. Some reports have demonstrated an amplification of IL toxicity due to an increase in the alkyl chain length of the cation [137]. Introduction of hydrophilic functional groups (e.g. hydroxyls, nitriles, and polar ethers) to the side chains of ILs decreases the toxicity of the IL cation due to a drop in hydrophobicity [137]. Compared to AILs (anionic ionic liquid), PILs (pyridinium ionic liquid) have exhibited reduced cytotoxicity due to their lack of bulky hydrophobic cations and perfluorinated anions [138]. Choline is FDA approved and choline-based ILs are substantially less toxic than an imidazolium- 
or pyridinium-based cation [137]. [Chol][DHP] was shown to be a biocompatible additive for the stabilization and formulation of recombinant human interleukin-2 (rHIL-2). It did not produce any toxic effects towards primary splenocytes and mouse melanoma cells (B16-F10) as well. From these reports, it is evident that the choline-based ILs could be attractive candidates for biocompatible ILs [139].

A good number of methods are available to study cytotoxicity. Among them the MTT assay is the most popular that is based on the mitochondrial enzymatic activity. The enzymes reduce the tetrazolium dye MTT (3-(4,5-dimethylthiazol-2-yl)-2,5diphenyltetrazolium bromide) or the related MTS, XTT, and WST dyes. Other methods such as fluorescence microscopy and apoptosis assays have shown that ILs promote oxidative stress, DNA damage, and apoptosis in cells.

Several ILs have been identified with cytotoxic activities by employing different human tumor cell lines. Among them a greater cytotoxicity was demonstrated by guanidinium ILs with long alkyl chains [140]. ILs that comprise of the tetrafluoroborate anions attached to natural amino acids also exhibited a marked cytotoxicity against a panel of tumor cell lines. Their cytotoxic mechanism was conceivably due to an elevation of toxic anion transport into the cells [141]. Nevertheless, to date no study has been conducted to evaluate the cytotoxic effect of ILs on tumor and normal cells. Compared to nonmalignant HEK (human embryonic kidney) cells, triethylammonium phosphate, 1methylimidazolium chloride, triethylammonium sulfate, and 1-butyl-3-methylimidazolium chloride furnished more cytotoxicity toward T98G brain cancer cells [127]. Interestingly, imidazolium-based ILs showed non-selectivity in terms of cytotoxicity toward normal human fibroblasts and $\mathrm{CaCo}-2$ (colorectal adenocarcinoma) cells [135].

A lower cytotoxicity was observed with cholinium ILs than with common cation-based imidazolium and pyridinium ILs. Right now, a major limitation lies in the fact that the cytotoxicity of ILs cannot be distinguished by their structure only since the type of cell strongly dictates the extent of cytotoxicity. An imidazolium-based IL called 1octyl-3-methylimidazolium chloride ([C8MIM][Cl]) was found to stimulate the expression of CYP450 genes and their products participated in xenobiotic metabolism in the mouse mammary carcinoma cell line EMT6 [142]. Other imidazolium ILs upregulated the multixenobiotic/multidrug resistance (MXR/MDR) system in HeLa cells. ${ }^{142}$ They also resulted in elevated oxidative stress, mitochondrial failure, and augmentation in apoptosis both in normal and malignant cells [141, 144-145]. ILs have also been reported to disrupt the lipid bilayers of cell membranes. For example, 1alkylquinolinium ILs damaged the cell membrane in $3 \mathrm{~T} 3$ cells [132]. To facilitate the development of effective anti-tumor agents by employing ILs, it is of utmost importance to know the mechanism of action which remains largely unexplored. Because of this, the potential use of ILs in the field of cancer is practically challenging. Hence, further studies are utterly required to explain the mechanistic impact of ILs in normal and tumor cells.

\section{CONCLUSION}

Ionic liquids have very diverse physicochemical properties. Their malleable physicochemical properties, such as stability, density, and mutual solubility, make them excellent candidates as excipients that can be used for multi-purposes. Their flexibility endows ingenuity to the researchers to formulate customized ILs that may serve unique purposes. So far, a good number of studies have reported the potential roles of ILs in drug delivery systems. Research on ILs has advanced beyond academia and currently chemical/pharmaceutical industries are extensively exploring the potential to utilize them in drug delivery systems. These ILs can be employed either as ingredients of drugs or drug delivery systems, or as facilitators/catalysts in reaction media and drug synthesis. Due to their wide range of physical properties it is possible that ionic liquids can be used in drug formulation development for both small molecule drugs and vaccines. In drug formulations they can be used as stabilizers, solubility enhancers, and permeability enhancers. On the other hand, these also can be used as vaccine stabilizers, penetration enhancers, and adjuvants in vaccine formulations. Cytotoxicity studies of ionic liquids also showed that the safe use of ionic liquids is possible in drug formulation development. Considering the above discussion, we foresee that ionic liquids hold an immense potential for their multi-purpose use in drug development.

\section{ACKNOWLEDGEMENT}

Authors acknowledge access computational resources provided by the CESNETLM2015042, the 
CERIT Scientific Cloud LM2015085, provided under the program "Projects of Large Research, Development, and Innovations Infrastructures". Authors also acknowledge Dr. Nicole Lounsbury for her input in preparing this manuscript.

\section{REFERENCES}

1. J.P. Hallett, T. Welton, Room-Temperature Ionic Liquids: Solvents for Synthesis and Catalysis. 2, Chemical Reviews. 111 (2011) 3508-3576. doi: $10.1021 / \operatorname{cr} 1003248$.

2. R. Hayes, G.G. Warr, R. Atkin, Structure and Nanostructure in Ionic Liquids, Chemical Reviews. 115 (2015) 6357-6426. doi:10.1021/cr500411q.

3. T. Welton, Room-Temperature Ionic Liquids. Solvents for Synthesis and Catalysis, Chemical Reviews. $99 \quad$ (1999) 2071-2084. doi:10.1021/cr980032t.

4. N. Meine, F. Benedito, R. Rinaldi, Thermal stability of ionic liquids assessed by potentiometric titration, Green Chemistry. 12 (2010) 1711. doi:10.1039/c0gc00091d.

5. S. Ahrens, A. Peritz, T. Strassner, Tunable Aryl Alkyl Ionic Liquids (TAAILs): The Next Generation of Ionic Liquids, Angewandte Chemie International Edition. 48 (2009) 7908-7910. doi:10.1002/anie.200903399.

6. R. Sheldon, Catalytic reactions in ionic liquids, Chemical Communications. (2001) 2399-2407. doi:10.1039/b107270f.

7. W. Zheng, W. Xie, W. Sun, L. Zhao, Modeling of the interfacial behaviors for the isobutane alkylation with $\mathrm{C} 4$ olefin using ionic liquid as catalyst, Chemical Engineering Science. 166 (2017) 42-52. doi:10.1016/j.ces.2017.02.049.

8. A.C. Grijalba, E.F. Fiorentini, R.G. Wuilloud, Ionic liquid-assisted separation and determination of selenium species in food and beverage samples by liquid chromatography coupled to hydride generation atomic fluorescence spectrometry, Journal of Chromatography A. 1491 (2017) 117125. doi:10.1016/j.chroma.2017.02.045.

9. S. Riaño, K. Binnemans, Extraction and separation of neodymium and dysprosium from used $\mathrm{NdFeB}$ magnets: an application of ionic liquids in solvent extraction towards the recycling of magnets, Green Chemistry. $17 \quad$ (2015) 2931-2942. doi:10.1039/c5gc00230c.

10. J. Eßer, P. Wasserscheid, A. Jess, Deep desulfurization of oil refinery streams by extraction with ionic liquids, Green Chem. 6 (2004) 316-322. doi:10.1039/b407028c.

11. M.H. Ibrahim, M. Hayyan, M.A. Hashim, A. Hayyan, The role of ionic liquids in desulfurization of fuels: A review, Renewable and Sustainable
Energy Reviews. 76 (2017) 1534-1549. doi:10.1016/j.rser.2016.11.194.

12. P.A. Suarez, J.E. Dullius, S. Einloft, R.F.D. Souza, J. Dupont, The use of new ionic liquids in twophase catalytic hydrogenation reaction by rhodium complexes, Polyhedron. 15 (1996) 1217-1219. doi:10.1016/0277-5387(95)00365-7.

13. L. Chen, C. Fink, Z. Fei, P.J. Dyson, G. Laurenczy, An efficient Pt nanoparticle-ionic liquid system for the hydrodeoxygenation of bio-derived phenols under mild conditions, Green Chemistry. 19 (2017) 5435-5441. doi:10.1039/c7gc01870c.

14. J. Fuller, The Room Temperature Ionic Liquid 1Ethyl-3-methylimidazolium Tetrafluoroborate: Electrochemical Couples and Physical Properties, Journal of The Electrochemical Society. 144 (1997) 3881. doi:10.1149/1.1838106.

15. A. Basile, A.I. Bhatt, A.P. O’Mullane, Stabilizing lithium metal using ionic liquids for long-lived batteries, Nature Communications. 7 (2016). doi:10.1038/ncomms11794.

16. P. Walden, Benzène comme dissolvant des électrolytes, Bulletin de l'Académie Impériale des Sciences de St.-Pétersbourg. VI série, 8:16 (1914), 1161-1186.

17. H.L. Chum, V.R. Koch, L.L. Miller, R.A. Osteryoung, Electrochemical scrutiny of organometallic iron complexes and hexamethylbenzene in a room temperature molten salt, Journal of the American Chemical Society. 97 (1975) 3264-3265. doi:10.1021/ja00844a081.

18. J.S. Wilkes, A short history of ionic liquids - from molten salts to neoteric solvents, Green Chemistry. 4 (2002) 73-80. doi:10.1039/b110838g.

19. L.A. Blanchard, D. Hancu, E.J. Beckman, J.F. Brennecke, Green processing using ionic liquids and CO2, Nature. 399 (1999) 28-29. doi:10.1038/19887.

20. J. Kröckel, U. Kragl, Nanofiltration for the Separation of Nonvolatile Products from Solutions Containing Ionic Liquids, Chemical Engineering \& Technology. $26 \quad$ (2003) 1166-1168. doi:10.1002/ceat.200301830.

21. P. Weerachanchai, J.-M. Lee, Recyclability of an ionic liquid for biomass pretreatment, Bioresource Technology. $\quad 169 \quad$ (2014) 336-343. doi:10.1016/j.biortech.2014.06.072.

22. N. Nie, L. Zhang, J. Fu, B. Cheng, J. Yu, Selfassembled hierarchical direct Z-scheme g$\mathrm{C} 3 \mathrm{~N} 4 / \mathrm{ZnO}$ microspheres with enhanced photocatalytic $\mathrm{CO} 2$ reduction performance, Applied Surface Science. 441 (2018) 12-22. doi:10.1016/j.apsusc.2018.01.193.

23. K.E. Gutowski, G.A. Broker, H.D. Willauer, J.G. Huddleston, R.P. Swatloski, J.D. Holbrey, et al., Controlling the Aqueous Miscibility of Ionic Liquids: Aqueous Biphasic Systems of Water- 
Miscible Ionic Liquids and Water-Structuring Salts for Recycle, Metathesis, and Separations, Journal of the American Chemical Society. 125 (2003) 6632-6633. doi:10.1021/ja0351802.

24. A. König, M. Stepanski, A. Kuszlik, P. Keil, C. Weller, Ultra-purification of ionic liquids by melt crystallization, Chemical Engineering Research and Design. $86 \quad$ (2008) 775-780. doi:10.1016/j.cherd.2008.04.002.

25. L. Cammarata, S.G. Kazarian, P.A. Salter, T. Welton, Molecular states of water in room temperature ionic liquids , Physical Chemistry Chemical Physics. 3 (2001) 5192-5200. doi:10.1039/b106900d.

26. P. Domínguez De María, "Nonsolvent" Applications of Ionic Liquids in Biotransformations and Organocatalysis, Angewandte Chemie International Edition. 47 (2008) 6960-6968. doi:10.1002/anie.200703305.

27. V. Blasucci, R. Hart, V.L. Mestre, D.J. Hahne, M. Burlager, H. Huttenhower, et al., Single component, reversible ionic liquids for energy applications, Fuel. 89 (2010) 1315-1319. doi:10.1016/j.fuel.2009.11.015.

28. F.H. Hurley, T.P. Wier, Electrodeposition of Metals from Fused Quaternary Ammonium Salts, Journal of The Electrochemical Society. 98 (1951) 203. doi:10.1149/1.2778132.

29. J. Robinson, R.A. Osteryoung, An electrochemical and spectroscopic study of some aromatic hydrocarbons in the room temperature molten salt system aluminum chloride-n-butylpyridinium chloride, Journal of the American Chemical Society. $101 \quad$ (1979) 323-327. doi:10.1021/ja00496a008.

30. J.S. Wilkes, J.A. Levisky, R.A. Wilson, C.L. Hussey, Dialkylimidazolium chloroaluminate melts: a new class of room-temperature ionic liquids for electrochemistry, spectroscopy and synthesis, Inorganic Chemistry. 21 (1982) 12631264. doi:10.1021/ic00133a078.

31. S.D. Williams, J.P. Schoebrechts, J.C. Selkirk, G. Mamantov, A new room temperature molten salt solvent system: organic cation tetrachloroborates, Journal of the American Chemical Society. 109 (1987) 2218-2219. doi:10.1021/ja00241a069.

32. Y. Chauvin, S. Einloft, H. Olivier, Catalytic Dimerization of Propene by Nickel-Phosphine Complexes in 1-Butyl-3-methylimidazolium Chloride/AlEtxCl3-x $(\mathrm{x}=0,1)$ Ionic Liquids, Industrial \& Engineering Chemistry Research. 34 (1995) 1149-1155. doi:10.1021/ie00043a017.

33. M. Deetlefs, K.R. Seddon, Improved preparations of ionic liquids using microwave irradiationThis work was presented at the Green Solvents for Catalysis Meeting held in Bruchsal, Germany, 13- 16th October 2002., Green Chemistry. 5 (2003) 181-186. doi:10.1039/b300071k.

34. Y. Chauvin, H. Olver-Bourbigou, Nonaqueous ionic liquids as reaction solvents, Chemtech. 25 (1995) 26-30.

35. C.A. Angell, Y. Ansari, Z. Zhao, Ionic Liquids: Past, present and future, Faraday Discuss. 154 (2012) 9-27. doi:10.1039/c1fd00112d.

36. S. Gabriel, J. Weiner, Ueber einige Abkömmlinge des Propylamins, Berichte Der Deutschen Chemischen Gesellschaft. 21 (1888) 2669-2679. doi:10.1002/cber.18880210288.

37. H. Markusson, J.-P. Belières, P. Johansson, C.A. Angell, P. Jacobsson, Prediction of Macroscopic Properties of Protic Ionic Liquids by Ab Initio Calculations, The Journal of Physical Chemistry A. 111 (2007) 8717-8723. doi:10.1021/jp072036k.

38. T.L. Greaves, C.J. Drummond, Protic Ionic Liquids: Properties and Applications, Chemical Reviews. $\quad 108 \quad$ (2008) 206-237. doi:10.1021/cr068040u.

39. M.S. Miran, H. Kinoshita, T. Yasuda, M.A.B.H. Susan, M. Watanabe, Hydrogen bonds in protic ionic liquids and their correlation with physicochemical properties, Chemical Communications. $\quad 47 \quad$ (2011) 12676. doi:10.1039/c1cc14817f.

40. K. Fumino, A. Wulf, R. Ludwig, Hydrogen Bonding in Protic Ionic Liquids: Reminiscent of Water, Angewandte Chemie International Edition. 48 (2009) 3184-3186. doi:10.1002/anie.200806224.

41. J. Ding, D.W. Armstrong, Chiral ionic liquids: Synthesis and applications, Chirality. 17 (2005) 281-292. doi:10.1002/chir.20153.

42. J.F.B. Pereira, P.S. Barber, S.P. Kelley, P. Berton, R.D. Rogers, Double salt ionic liquids based on 1ethyl-3-methylimidazolium acetate and hydroxylfunctionalized ammonium acetates: strong effects of weak interactions, Phys. Chem. Chem. Phys. 19 (2017) 26934-26943. doi:10.1039/c7cp05710e.

43. D. Mecerreyes, Polymeric ionic liquids: Broadening the properties and applications of polyelectrolytes, Progress in Polymer Science. 36 (2011) 1629-1648. doi:10.1016/j.progpolymsci.2011.05.007.

44. K. Takechi, Y. Kato, Y. Hase, A Highly Concentrated Catholyte Based on a Solvate Ionic Liquid for Rechargeable Flow Batteries, Advanced Materials. $27 \quad$ (2015) 2501-2506. doi:10.1002/adma.201405840.

45. H. Doi, X. Song, B. Minofar, R. Kanzaki, T. Takamuku, Y. Umebayashi, A New Proton Conductive Liquid with No Ions: Pseudo-Protic Ionic Liquids, Chemistry - A European Journal. 19 (2013) 11522-11526. doi:10.1002/chem.201302228. 
46. M. Yoshizawa, W. Xu, C.A. Angell, Ionic Liquids by Proton Transfer: Vapor Pressure, Conductivity, and the Relevance of $\Delta$ pKafrom Aqueous Solutions, Journal of the American Chemical Society. $125 \quad$ (2003) 15411-15419. doi:10.1021/ja035783d.

47. C.F. Poole, Chromatographic and spectroscopic methods for the determination of solvent properties of room temperature ionic liquids, Journal of Chromatography A. 1037 (2004) 49-82. doi:10.1016/j.chroma.2003.10.127.

48. E. Janus, I. Goc-Maciejewska, M. Łożyński, J. Pernak, Diels-Alder reaction in protic ionic liquids, Tetrahedron Letters. 47 (2006) 4079-4083. doi:10.1016/j.tetlet.2006.03.172.

49. A. Zhu, T. Jiang, D. Wang, B. Han, L. Liu, J. Huang, et al., Direct aldol reactions catalyzed by 1,1,3,3-tetramethylguanidine lactate without solvent, Green Chemistry. 7 (2005) 514. doi: $10.1039 / \mathrm{b} 501925 \mathrm{~g}$.

50. H. Nakamoto, M. Watanabe, Brønsted acid-base ionic liquids for fuel cell electrolytes, Chem. Commun. (2007) 2539-2541. doi:10.1039/b618953a.

51. N.B. Darvatkar, A.R. Deorukhkar, S.V. Bhilare, M.M. Salunkhe, Ionic Liquid-Mediated Knoevenagel Condensation of Meldrums Acid and Aldehydes, Synthetic Communications. 36 (2006) 3043-3051. doi:10.1080/00397910600775218.

52. L.C. Henderson, N. Byrne, Rapid and efficient protic ionic liquid-mediated pinacol rearrangements under microwave irradiation, $\begin{array}{lllll}\text { Green } & \text { Chemistry. } & 13 & \text { (2011) } 813 .\end{array}$ doi:10.1039/c0gc00916d.

53. H. Shi, W. Zhu, H. Li, H. Liu, M. Zhang, Y. Yan, et al., Microwave-accelerated esterification of salicylic acid using Brönsted acidic ionic liquids as catalysts, Catalysis Communications. 11 (2010) 588-591. doi:10.1016/j.catcom.2009.12.025.

54. X. Tong, Y. Li, Efficient and Selective Dehydration of Fructose to 5Hydroxymethylfurfural Catalyzed by BrønstedAcidic Ionic Liquids, ChemSusChem. 3 (2010) 350-355. doi:10.1002/cssc.200900224.

55. X. Li, W. Eli, G. Li, Solvent-free synthesis of benzoic esters and benzyl esters in novel Brønsted acidic ionic liquids under microwave irradiation, Catalysis Communications. 9 (2008) 2264-2268. doi:10.1016/j.catcom.2008.05.015.

56. F.E. Etzler, M. N. Uddin, Powder technology and pharmaceutical development: Particle size and particle adhesion, KONA Powder and particle Journal, 2013, No 13, Page 125-143. https://doi.org/10.14356/kona.2013014.

57. J.P. Armstrong, C. Hurst, R.G. Jones, P. Licence, K.R.J. Lovelock, C.J. Satterley, et al., Vapourisation of ionic liquids, Physical Chemistry
Chemical Physics. 9 (2007) 982. doi:10.1039/b615137j.

58. A. Vahid, E.J. Maginn, Monte Carlo simulation and SAFT modeling study of the solvation thermodynamics of dimethylformamide, dimethylsulfoxide, ethanol and 1-propanol in the ionic liquid trimethylbutylammonium bis(trifluoromethylsulfonyl)imide, Physical Chemistry Chemical Physics. 17 (2015) 74497462. doi:10.1039/c4cp05961a.

59. T. Köddermann, D. Paschek, R. Ludwig, Ionic Liquids: Dissecting the Enthalpies of Vaporization, ChemPhysChem. 9 (2008) 549-555. doi:10.1002/cphc.200700814.

60. K. Fumino, A. Wulf, S.P. Verevkin, A. Heintz, R. Ludwig, Estimating Enthalpies of Vaporization of Imidazolium-Based Ionic Liquids from FarInfrared Measurements, ChemPhysChem. 11 (2010) 1623-1626. doi:10.1002/cphc.201000140.

61. S.D. Chambreau, G.L. Vaghjiani, A. To, C. Koh, D. Strasser, O. Kostko, et al., Heats of Vaporization of Room Temperature Ionic Liquids by Tunable Vacuum Ultraviolet Photoionization, The Journal of Physical Chemistry B. 114 (2010) 1361-1367. doi:10.1021/jp909423m.

62. C. Wang, H. Luo, H. Li, S. Dai, Direct UVspectroscopic measurement of selected ionic-liquid vapors, Physical Chemistry Chemical Physics. 12 (2010) 7246. doi:10.1039/c001101k.

63. T. Cremer, L. Wibmer, S.K. Calderón, A. Deyko, F. Maier, H.-P. Steinrück, Interfaces of ionic liquids and transition metal surfaces-adsorption, growth, and thermal reactions of ultrathin $[\mathrm{C} 1 \mathrm{C} 1 \mathrm{Im}][\mathrm{Tf} 2 \mathrm{~N}]$ films on metallic and oxidised Ni(111) surfaces, Physical Chemistry Chemical Physics. 14 (2012) 5153. doi:10.1039/c2cp40278e.

64. U. Domańska, Z. Żołek-Tryznowska, M. Królikowski, Thermodynamic Phase Behavior of Ionic Liquids, Journal of Chemical \& Engineering Data. $52 \quad$ (2007) 1872-1880. doi:10.1021/je700204d.

65. P. Gabbott, Principles and applications of thermal analysis, Blackwell Pub., Oxford, 2008.

66. J.-P. Belieres, C.A. Angell, Protic Ionic Liquids: Preparation, Characterization, and Proton Free Energy Level Representation $\dagger$, The Journal of Physical Chemistry B. 111 (2007) 4926-4937. doi:10.1021/jp067589u.

67. M. Kosmulski, J. Gustafsson, J.B. Rosenholm, Thermal stability of low temperature ionic liquids revisited, Thermochimica Acta. 412 (2004) 47-53. doi:10.1016/j.tca.2003.08.022.

68. A.W.T. King, A. Parviainen, P. Karhunen, J. Matikainen, L.K.J. Hauru, H. Sixta, et al., Relative and inherent reactivities of imidazolium-based ionic liquids: the implications for lignocellulose 
processing applications, RSC Advances. 2 (2012) 8020. doi:10.1039/c2ra21287k.

69. H. Tokuda, S. Tsuzuki, M.A.B.H. Susan, K. Hayamizu, M. Watanabe, How Ionic Are RoomTemperature Ionic Liquids? An Indicator of the Physicochemical Properties, The Journal of Physical Chemistry B. 110 (2006) 19593-19600. doi:10.1021/jp064159v.

70. A.G. Glenn, P.B. Jones, Thermal stability of ionic liquid $\mathrm{BMI}(\mathrm{BF} 4)$ in the presence of nucleophiles, Tetrahedron Letters. 45 (2004) 6967-6969. doi:10.1016/j.tetlet.2004.07.050.

71. E.M. Siedlecka, M. Czerwicka, S. Stolte, P. Stepnowski, Stability of Ionic Liquids in Application Conditions, Current Organic Chemistry. $\quad 15 \quad$ (2011) 1974-1991. doi:10.2174/138527211795703630.

72. Y. Chen, Y. Cao, Y. Shi, Z. Xue, T. Mu, Quantitative Research on the Vaporization and Decomposition of [EMIM][Tf2N] by Thermogravimetric Analysis-Mass Spectrometry, Industrial \& Engineering Chemistry Research. 51 (2012) 7418-7427. doi:10.1021/ie300247v.

73. W.H. Awad, J.W. Gilman, M. Nyden, R.H. Harris, T.E. Sutto, J. Callahan, et al., Thermal degradation studies of alkyl-imidazolium salts and their application in nanocomposites, Thermochimica Acta. 409 (2004) 3-11. doi:10.1016/s00406031(03)00334-4.

74. H. Ohtani, S. Ishimura, M. Kumai, Thermal Decomposition Behaviors of Imidazolium-type Ionic Liquids Studied by Pyrolysis-Gas Chromatography, Analytical Sciences. 24 (2008) 1335-1340. doi:10.2116/analsci.24.1335.

75. M.T. Clough, K. Geyer, P.A. Hunt, J. Mertes, T. Welton, Thermal decomposition of carboxylate ionic liquids: trends and mechanisms, Physical Chemistry Chemical Physics. 15 (2013) 20480. doi:10.1039/c3cp53648c.

76. D. Fox, J. Gilman, H.D. Long, P. Trulove, TGA decomposition kinetics of 1-butyl-2,3dimethylimidazolium tetrafluoroborate and the thermal effects of contaminants, The Journal of Chemical Thermodynamics. 37 (2005) 900-905. doi:10.1016/j.jct.2005.04.020.

77. R.E.D. Sesto, T.M. Mccleskey, C. Macomber, K.C. Ott, A.T. Koppisch, G.A. Baker, et al., Limited thermal stability of imidazolium and pyrrolidinium ionic liquids, Thermochimica Acta. 491 (2009) 118-120. doi:10.1016/j.tca.2009.02.023.

78. K.J. Baranyai, G.B. Deacon, D.R. Macfarlane, J.M. Pringle, J.L. Scott, Thermal Degradation of Ionic Liquids at Elevated Temperatures, Australian Journal of Chemistry. 57 (2004) 145. doi: $10.1071 / \operatorname{ch} 03221$.

79. J. Jacquemin, R. Ge, P. Nancarrow, D.W. Rooney, M.F.C. Gomes, A.A.H. Pádua, et al., Prediction of
Ionic Liquid Properties. I. Volumetric Properties as a Function of Temperature at $0.1 \mathrm{MPa}$, Journal of Chemical \& Engineering Data. 53 (2008) 716-726. doi:10.1021/je700707y.

80. R.A. Mantz, P.C. Trulove, Ionic Liquids in Synthesis, Physicochemical Properties. (2007). doi:10.1002/9783527621194.

81. D.B. Sirdeshmukh, L. Sirdeshmukh, K.G. Subhadra, Structure-Related Parameters, Alkali Halides Springer Series in Materials Science. (2001) 1-14. doi:10.1007/978-3-662-04341-7_1.

82. A.A. Fannin, D.A. Floreani, L.A. King, J.S. Landers, B.J. Piersma, D.J. Stech, et al., Properties of 1,3-dialkylimidazolium chloride-aluminum chloride ionic liquids. 2. Phase transitions, densities, electrical conductivities, and viscosities, The Journal of Physical Chemistry. 88 (1984) 2614-2621. doi:10.1021/j150656a038.

83. J.M. Crosthwaite, S.N.V.K. Aki, E.J. Maginn, J.F. Brennecke, Liquid Phase Behavior of Imidazolium-Based Ionic Liquids with Alcohols, The Journal of Physical Chemistry B. 108 (2004) 5113-5119. doi:10.1021/jp037774x.

84. A. Heintz, J.K. Lehmann, C. Wertz, Thermodynamic Properties of Mixtures Containing Ionic Liquids. 3. Liquid-Liquid Equilibria of Binary Mixtures of 1-Ethyl-3-methylimidazolium Bis(trifluoromethylsulfonyl)imide with Propan-1ol, Butan-1-ol, and Pentan-1-ol†, Journal of Chemical \& Engineering Data. 48 (2003) 472-474. doi: $10.1021 / \mathrm{je} 0201931$.

85. A. Chapeaux, L.D. Simoni, M.A. Stadtherr, J.F. Brennecke, Liquid Phase Behavior of Ionic Liquids with Water and 1-Octanol and Modeling of 1Octanol/Water Partition Coefficients, Journal of Chemical \& Engineering Data. 52 (2007) 24622467. doi:10.1021/je7003935.

86. M.G. Freire, C.M.S.S. Neves, P.J. Carvalho, R.L. Gardas, A.M. Fernandes, I.M. Marrucho, et al., Mutual Solubilities of Water and Hydrophobic Ionic Liquids, The Journal of Physical Chemistry B. $111 \quad$ (2007) 13082-13089. doi:10.1021/jp076271e.

87. H.A. Every, A.G. Bishop, D.R. Macfarlane, G. Orädd, M. Forsyth, Transport properties in a family of dialkylimidazolium ionic liquids, Phys. Chem. Chem. Phys. 6 (2004) 1758-1765. doi:10.1039/b315813f.

88. J.L. Shamshina, S.P. Kelley, G. Gurau, R.D. Rogers, Chemistry: Develop ionic liquid drugs, Nature. $\quad 528 \quad$ (2015) 188-189. doi:10.1038/528188a.

89. Z. Elgundi, M. Reslan, E. Cruz, V. Sifniotis, V. Kayser, The state-of-play and future of antibody therapeutics, Advanced Drug Delivery Reviews. 122 (2017) 2-19. doi:10.1016/j.addr.2016.11.004. 
90. S. Yamaguchi, E. Yamamoto, S. Tsukiji, T. Nagamune, Successful Control of Aggregation and Folding Rates during Refolding of Denatured Lysozyme by Adding N-Methylimidazolium Cations with Various N-Substituents, Biotechnology Progress. 24 (2008) 402-408. doi:10.1021/bp070207x.

91. P.K. Kumar, I. Jha, P. Venkatesu, I. Bahadur, E.E. Ebenso, A comparative study of the stability of stem bromelain based on the variation of anions of imidazolium-based ionic liquids, Journal of Molecular Liquids. 246 (2017) 178-186. doi:10.1016/j.molliq.2017.09.037.

92. T. Takekiyo, Y. Ishikawa, Y. Yoshimura, Cryopreservation of Proteins Using Ionic Liquids: A Case Study of Cytochrome c, The Journal of Physical Chemistry B. 121 (2017) 7614-7620. doi:10.1021/acs.jpcb.7b05158.

93. R. Buchfink, A. Tischer, G. Patil, R. Rudolph, C. Lange, Ionic liquids as refolding additives: Variation of the anion, Journal of Biotechnology. 150 (2010) 64-72. doi:10.1016/j.jbiotec.2010.07.003.

94. P. Attri, P. Venkatesu, A. Kumar, Activity and stability of $\alpha$-chymotrypsin in biocompatible ionic liquids: enzyme refolding by triethyl ammonium acetate, Phys. Chem. Chem. Phys. 13 (2011) 27882796. doi:10.1039/c0cp01291b.

95. C. Lange, G. Patil, R. Rudolph, Ionic liquids as refolding additives: $\mathrm{N}^{\prime}$-alkyl and $\mathrm{N}^{\prime}-(\omega-$ hydroxyalkyl) N-methylimidazolium chlorides, Protein Science. 14 (2005) 2693-2701. doi:10.1110/ps.051596605.

96. K. Fujita, D.R. Macfarlane, M. Forsyth, M. Yoshizawa-Fujita, K. Murata, N. Nakamura, et al., Solubility and Stability of Cytochromecin Hydrated Ionic Liquids: Effect of Oxo Acid Residues and Kosmotropicity, Biomacromolecules. 8 (2007) 2080-2086. doi:10.1021/bm070041o.

97. K.D. Weaver, R.M. Vrikkis, M.P.V. Vorst, J. Trullinger, R. Vijayaraghavan, D.M. Foureau, et $a l$., Structure and function of proteins in hydrated choline dihydrogen phosphate ionic liquid, Phys. Chem. Chem. Phys. 14 (2012) 790-801. doi:10.1039/c1cp22965f.

98. R.R. Mazid, R. Vijayaraghavan, D.R. Macfarlane, C. Cortez-Jugo, W. Cheng, Inhibited fragmentation of mAbs in buffered ionic liquids, Chemical Communications. $51 \quad$ (2015) 8089-8092. doi:10.1039/c5ec01877c.

99. J.V. Rodrigues, V. Prosinecki, I. Marrucho, L.P.N. Rebelo, C.M. Gomes, Protein stability in an ionic liquid milieu: on the use of differential scanning fluorimetry, Physical Chemistry Chemical Physics. 13 (2011) 13614. doi:10.1039/c1cp21187k.
100. M. Bisht, D. Mondal, M.M. Pereira, M.G. Freire, P. Venkatesu, J.A.P. Coutinho, Long-term protein packaging in cholinium-based ionic liquids: improved catalytic activity and enhanced stability of cytochrome c against multiple stresses, Green Chemistry. $\quad 19 \quad$ (2017) 4900-4911. doi:10.1039/c7gc02011b.

101. A. Tarannum, J.R. Rao, N.N. Fathima, CholineBased Amino Acid ILs-Collagen Interaction: Enunciating Its Role in Stabilization/Destabilization Phenomena, The Journal of Physical Chemistry B. 122 (2018) 11451151. doi:10.1021/acs.jpcb.7b10645.

102. S. Kandasamy, M. Moniruzzaman, M. Sivapragasam, M.R. Shamsuddin, M.I.A. Mutalib, Formulation and characterization of acetate based ionic liquid in oil microemulsion as a carrier for acyclovir and methotrexate, Separation and Purification Technology. 196 (2018) 149-156. doi:10.1016/j.seppur.2017.08.044.

103. H. Yoshiura, M. Tamura, M. Aso, N. Kamiya, M. Goto, Ionic Liquid-in-Oil Microemulsions as Potential Carriers for the Transdermal Delivery of Methotrexate, Journal Of Chemical Engineering Of Japan. $\quad 46 \quad$ (2013) 794-796. doi:10.1252/jcej.13we009.

104. K. Kubota, A. Shibata, T. Yamaguchi, The molecular assembly of the ionic liquid/aliphatic carboxylic acid/aliphatic amine as effective and safety transdermal permeation enhancers, European Journal of Pharmaceutical Sciences. 86 (2016) 75-83. doi:10.1016/j.ejps.2016.03.002.

105. S.-Y. Furukawa, G. Hattori, S. Sakai, N. Kamiya, Highly efficient and low toxic skin penetrants composed of amino acid ionic liquids, RSC Advances. $6 \quad$ (2016) 87753-87755. doi:10.1039/c6ra16926k.

106. D. Monti, E. Egiziano, S. Burgalassi, P. Chetoni, C. Chiappe, A. Sanzone, et al., Ionic liquids as potential enhancers for transdermal drug delivery, International Journal of Pharmaceutics. 516 (2017) 45-51. doi:10.1016/j.ijpharm.2016.11.020.

107. M. Zakrewsky, K.S. Lovejoy, T.L. Kern, T.E. Miller, V. Le, A. Nagy, et al., Ionic liquids as a class of materials for transdermal delivery and pathogen neutralization, Proceedings of the National Academy of Sciences. 111 (2014) 1331313318. doi:10.1073/pnas.1403995111.

108. D.J. Smith, J.K. Shah, E.J. Maginn, Molecular Dynamics Simulation Study of the Association of Lidocainium Docusate and Its Derivatives in Aqueous Solution, Molecular Pharmaceutics. 12 (2015) 1893-1901. doi:10.1021/mp5005993.

109. D. Dobler, T. Schmidts, I. Klingenhöfer, F. Runkel, Ionic liquids as ingredients in topical drug delivery systems, International Journal of 
Pharmaceutics. $441 \quad$ (2013) 620-627. doi:10.1016/j.ijpharm.2012.10.035.

110. S. Araki, R. Wakabayashi, M. Moniruzzaman, N. Kamiya, M. Goto, Ionic liquid-mediated transcutaneous protein delivery with solid-in-oil nanodispersions, MedChemComm. 6 (2015) 2124 2128. doi: $10.1039 / \mathrm{c} 5 \mathrm{md} 00378 \mathrm{~d}$.

111. H.D. Williams, L. Ford, S. Lim, S. Han, J. Baumann, H. Sullivan, et al., Transformation of Biopharmaceutical Classification System Class I and III Drugs Into Ionic Liquids and Lipophilic Salts for Enhanced Developability Using Lipid Formulations, Journal of Pharmaceutical Sciences. 107 (2018) 203-216. doi:10.1016/j.xphs.2017.05.019.

112. Y. Sahbaz, T.-H. Nguyen, L. Ford, C.L. Mcevoy, H.D. Williams, P.J. Scammells, et al., Ionic Liquid Forms of Weakly Acidic Drugs in Oral Lipid Formulations: Preparation, Characterization, in Vitro Digestion, and in Vivo Absorption Studies, Molecular Pharmaceutics. 14 (2017) 3669-3683. doi:10.1021/acs.molpharmaceut.7b00442.

113. Y. Sahbaz, H.D. Williams, T.-H. Nguyen, J. Saunders, L. Ford, S.A. Charman, et al., Transformation of Poorly Water-Soluble Drugs into Lipophilic Ionic Liquids Enhances Oral Drug Exposure from Lipid Based Formulations, Molecular Pharmaceutics. 12 (2015) 1980-1991. doi: $10.1021 / \mathrm{mp} 500790 \mathrm{t}$.

114. K.S. Egorova, E.G. Gordeev, V.P. Ananikov, Biological Activity of Ionic Liquids and Their Application in Pharmaceutics and Medicine, Chemical Reviews. 117 (2017) 7132-7189. doi:10.1021/acs.chemrev.6b00562.

115. N. Byrne, B. Rodoni, F. Constable, S. Varghese, J.H. Davis, Enhanced stabilization of the Tobacco mosaic virus using protic ionic liquids, Physical Chemistry Chemical Physics. 14 (2012) 10119. doi:10.1039/c2cp41625e.

116. V. Kayser, N. Chennamsetty, V. Voynov, B. Helk, K. Forrer, B.L. Trout, Evaluation of a NonArrhenius Model for Therapeutic Monoclonal Antibody Aggregation, Journal of Pharmaceutical Sciences. $100 \quad$ (2011) 2526-2542. doi:10.1002/jps.22493.

117. P.-A. Albertsson, Partition of Cell Particles and Macromolecules in Polymer Two-Phase Systems, Advances in Protein Chemistry Advances in Protein Chemistry Volume 24. (1970) 309-341. doi:10.1016/s0065-3233(08)60244-2.

118. J.F.B. Pereira, Á.S. Lima, M.G. Freire, J.A.P. Coutinho, Ionic liquids as adjuvants for the tailored extraction of biomolecules in aqueous biphasic systems, Green Chemistry. 12 (2010) 1661. doi: $10.1039 / \mathrm{c} 003578 \mathrm{e}$.

119. R.L.D. Souza, V.C. Campos, S.P. Ventura, C.M. Soares, J.A. Coutinho, Á.S. Lima, Effect of ionic liquids as adjuvants on PEG-based ABS formation and the extraction of two probe dyes, Fluid Phase Equilibria. $375 \quad$ (2014) 30-36. doi:10.1016/j.fluid.2014.04.011.

120. M.R. Almeida, H. Passos, M.M. Pereira, Á.S. Lima, J.A. Coutinho, M.G. Freire, Ionic liquids as additives to enhance the extraction of antioxidants in aqueous two-phase systems, Separation and Purification Technology. 128 (2014) 1-10. doi:10.1016/j.seppur.2014.03.004.

121. A.M. Ferreira, V.F. Faustino, D. Mondal, J.A. Coutinho, M.G. Freire, Improving the extraction and purification of immunoglobulin $\mathrm{G}$ by the use of ionic liquids as adjuvants in aqueous biphasic systems, Journal of Biotechnology. 236 (2016) 166-175. doi:10.1016/j.jbiotec.2016.08.015.

122. N.F.H.A. Aziz, S. Abbasiliasi, H.S. Ng, P. Phapugrangkul, M.H.A. Bakar, Y.J. Tam, et al., Purification of $\beta$-mannanase derived from Bacillus subtilis ATCC 11774 using ionic liquid as adjuvant in aqueous two-phase system, Journal of Chromatography B. 1055-1056 (2017) 104-112. doi:10.1016/j.jchromb.2017.04.029.

123. R.L.D. Souza, V.C. Campos, S.P. Ventura, C.M. Soares, J.A. Coutinho, Á.S. Lima, Effect of ionic liquids as adjuvants on PEG-based ABS formation and the extraction of two probe dyes, Fluid Phase Equilibria. $375 \quad$ (2014) 30-36. doi:10.1016/j.fluid.2014.04.011.

$124 . \quad$ R.L. Souza, S.P.M. Ventura, C.M.F. Soares, J.A.P. Coutinho, Á.S. Lima, Lipase purification using ionic liquids as adjuvants in aqueous two-phase systems, Green Chemistry. 17 (2015) 3026-3034. doi: $10.1039 / \mathrm{c} 5 \mathrm{gc} 00262 \mathrm{a}$.

125. C.M. Neves, R.D.C.S. Sousa, M.M. Pereira, M.G. Freire, J.A. Coutinho, Understanding the effect of ionic liquids as adjuvants in the partition of biomolecules in aqueous two-phase systems formed by polymers and weak salting-out agents, Biochemical Engineering Journal. 141 (2019) 239246. doi:10.1016/j.bej.2018.10.022.

126. V. Kumar, S.V. Malhotra, Study on the potential anti-cancer activity of phosphonium and ammonium-based ionic liquids, Bioorganic \& Medicinal Chemistry Letters. 19 (2009) 46434646. doi:10.1016/j.bmcl.2009.06.086.

127. N. Kaushik, P. Attri, N. Kaushik, E. Choi, Synthesis and Antiproliferative Activity of Ammonium and Imidazolium Ionic Liquids against T98G Brain Cancer Cells, Molecules. 17 (2012) 13727-13739. doi:10.3390/molecules171213727.

128. N. Gal, D. Malferarri, S. Kolusheva, P. Galletti, E. Tagliavini, R. Jelinek, Membrane interactions of ionic liquids: Possible determinants for biological activity and toxicity, Biochimica Et Biophysica Acta (BBA) - Biomembranes. 1818 (2012) 29672974. doi:10.1016/j.bbamem.2012.07.025. 
129. P. Stepnowski, A.C. Skladanowski, A. Ludwiczak, E. Laczyńska, Evaluating the cytotoxicity of ionic liquids using human cell line HeLa, Human \& Experimental Toxicology. 23 (2004) 513-517. doi:10.1191/0960327104ht480oa.

130. H.-L. Chen, H.-F. Kao, J.-Y. Wang, G.-T. Wei, Cytotoxicity of Imidazole Ionic Liquids in Human Lung Carcinoma A549 Cell Line, Journal of the Chinese Chemical Society. 61 (2014) 763-769. doi:10.1002/jccs.201300632.

131. S.V. Malhotra, V. Kumar, C. Velez, B. Zayas, Imidazolium-derived ionic salts induce inhibition of cancerous cell growth through apoptosis, Med. Chem. Commun. 5 (2014) 1404-1409. doi: $10.1039 / \mathrm{c} 4 \mathrm{md} 00161 \mathrm{c}$.

132. M. Mclaughlin, M.J. Earle, M.A. Gîlea, B.F. Gilmore, S.P. Gorman, K.R. Seddon, Cytotoxicity of 1-alkylquinolinium bromide ionic liquids in murine fibroblast NIH $3 \mathrm{~T} 3$ cells, Green Chemistry. 13 (2011) 2794. doi:10.1039/c0gc00813c.

133. J. Ranke, K. Mölter, F. Stock, U. Bottin-Weber, J. Poczobutt, J. Hoffmann, et al., Biological effects of imidazolium ionic liquids with varying chain lengths in acute Vibrio fischeri and WST-1 cell viability assays, Ecotoxicology and Environmental Safety. 58 (2004) 396-404. doi:10.1016/s01476513(03)00105-2.

134. T. Schaffran, E. Justus, M. Elfert, T. Chen, D. Gabel, Toxicity of N,N,Ntrialkylammoniododecaborates as new anions of ionic liquids in cellular, liposomal and enzymatic test systems, Green Chemistry. 11 (2009) 1458. doi:10.1039/b906165g.

135. K.S. Egorova, M.M. Seitkalieva, A.V. Posvyatenko, V.N. Khrustalev, V.P. Ananikov, Cytotoxic Activity of Salicylic Acid-Containing Drug Models with Ionic and Covalent Binding, ACS Medicinal Chemistry Letters. 6 (2015) 10991104. doi:10.1021/acsmedchemlett.5b00258.

136. R.F. Frade, C.A. Afonso, Impact of ionic liquids in environment and humans: An overview, Human \& Experimental Toxicology. 29 (2010) 1038-1054. doi:10.1177/0960327110371259.

137. R.A. Kumar, N. Papaïconomou, J.-M. Lee, J. Salminen, D.S. Clark, J.M. Prausnitz, In vitrocytotoxicities of ionic liquids: Effect of cation rings, functional groups, and anions, Environmental Toxicology. 24 (2009) 388-395. doi:10.1002/tox.20443.

138. W. Gouveia, T. Jorge, S. Martins, M. Meireles, M. Carolino, C. Cruz, et al., Toxicity of ionic liquids prepared from biomaterials, Chemosphere. 104 (2014) 51-56. doi:10.1016/j.chemosphere.2013.10.055.

139. D.M. Foureau, R.M. Vrikkis, C.P. Jones, K.D. Weaver, D.R. Macfarlane, J.C. Salo, et al., In Vitro Assessment of Choline Dihydrogen Phosphate
(CDHP) as a Vehicle for Recombinant Human Interleukin-2 (rhIL-2), Cellular and Molecular Bioengineering. 5 (2012) 390-401. doi:10.1007/s12195-012-0243-x.

140. K. Cook, K Tarnawsky, A. J. Swinton, D. D. Yang, A. S. Senetra, G. A. Caputo, B. R. Carone, T. D. Vaden, Correlating Lipid Membrane Permeabilities of Imidazolium Ionic Liquids with Their Cytotoxicities on Yeast, Bacterial, and Mammalian Cells. Biomolecules. 2019 Jun; 9(6): 251. doi: 10.3390/biom 9060251

141. K.S. Egorova, M.M. Seitkalieva, A.V. Posvyatenko, V.P. Ananikov, An unexpected increase of toxicity of amino acid-containing ionic liquids, Toxicology Research. 4 (2015) 152-159. doi:10.1039/c4tx00079j.

142. X. Li, J. Ma, C. Jing, J. Wang, Expression alterations of cytochromes P4501A1, 2E1, and 3A, and their receptors AhR and PXR caused by 1octyl-3-methylimidazolium chloride in mouse mammary carcinoma cells, Chemosphere. 93 (2013) 2488-2492. doi:10.1016/j.chemosphere.2013.08.092.

143. I. Rusiecka, A.C. Składanowski, Induction of the multixenobiotic/multidrug resistance system in HeLa cells in response to imidazolium ionic liquids., Acta Biochimica Polonica. 58 (2011). doi:10.18388/abp.2011_2263.

144. X.-Y. Li, S.-H. Zeng, X.-Y. Dong, J.-G. Ma, J.-J. Wang, Acute toxicity and responses of antioxidant systems to 1-methyl-3-octylimidazolium bromide at different developmental stages of goldfish, Ecotoxicology. $21 \quad$ (2011) 253-259. doi:10.1007/s10646-011-0785-z.

145. X.-Y. Li, C.-Q. Jing, W.-L. Lei, J. Li, J.-J. Wang, Apoptosis caused by imidazolium-based ionic liquids in $\mathrm{PC} 12$ cells, Ecotoxicology and Environmental Safety. 83 (2012) 102-107. doi:10.1016/j.ecoenv.2012.06.013.

146. A.F.M. Cláudio, M.C. Neves, K. Shimizu, J.N.C. Lopes, M.G. Freire, J.A.P. Coutinho, The magic of aqueous solutions of ionic liquids: ionic liquids as a powerful class of catanionic hydrotropes, Green Chemistry. $17 \quad$ (2015) 3948-3963. doi:10.1039/c5gc00712g.

147. M.A. Alawi, I.I. Hamdan, A.A. Sallam, N.A. Heshmeh, Solubility enhancement of glibenclamide in choline-tryptophan ionic liquid: Preparation, characterization and mechanism of solubilization, Journal of Molecular Liquids. 212 (2015) 629-634. doi:10.1016/j.molliq.2015.10.006.

148. M. Bisht, D. Mondal, M.M. Pereira, M.G. Freire, P. Venkatesu, J.A.P. Coutinho, Long-term protein packaging in cholinium-based ionic liquids: improved catalytic activity and enhanced stability of cytochrome c against multiple stresses, Green 
Chemistry. $\quad 19 \quad$ (2017) 4900-4911. doi:10.1039/c7gc02011b.

149. D.J. Smith, J.K. Shah, E.J. Maginn, Molecular Dynamics Simulation Study of the Association of Lidocainium Docusate and Its Derivatives in Aqueous Solution, Molecular Pharmaceutics. 12 (2015) 1893-1901. doi:10.1021/mp5005993.

150. S.T. Cromie, Pópolo M. G. Del, P. Ballone, Interaction of Room Temperature Ionic Liquid
Solutions with a Cholesterol Bilayer, The Journal of Physical Chemistry B. 113 (2009) 1164211648. doi:10.1021/jp904060y.

151. J.H. An, F. Jin, H.S. Kim, H.C. Ryu, J.S. Kim, H.M. Kim, et al., Investigation of the Polymorphic Transformation of the Active Pharmaceutical Ingredient Clopidogrel Bisulfate Using the Ionic Liquid AEImBF4, Crystal Growth \& Design. 16 (2016) 1829-1836. doi:10.1021/acs.cgd.5b01079. 